\title{
Noncoding RNA control of the making and breaking of sugars
}

\author{
Boris Görke ${ }^{1}$ and Jörg Vogel ${ }^{2,3}$ \\ ${ }^{1}$ Department of General Microbiology, Georg August University Göttingen, D-37077 Göttingen, Germany; ${ }^{2}$ RNA Biology \\ Group, Max Planck Institute for Infection Biology, D-10117 Berlin, Germany
}

\begin{abstract}
Noncoding RNA regulators have been implicated in almost all imaginable cellular processes. Here we review how regulatory small RNAs such as Spot42, SgrS, GlmY, and $G \operatorname{lmZ}$ and a cis-encoded ribozyme in $\operatorname{glm} S$ mRNA control sugar metabolism. Besides discussing the physiological implications, we show how the study of these molecules contributed to our understanding of the mechanisms and of general principles of RNA-based regulation. These include the post-transcriptional repression or activation of gene expression within polycistronic mRNAs; novel ribonucleoprotein complexes composed of small RNA, Hfq, and/or RNase E; and the hierarchical action of regulatory RNAs.
\end{abstract}

Any life on earth depends on carbohydrates, which provide cells with energy and the building blocks for biosynthesis of all macromolecules. It is therefore not surprising that the uptake and metabolism of carbohydrates are extensively regulated at all levels. Organisms typically express the genes required for the utilization of a particular sugar substrate only if it is available in the environment. Regulation of the Escherichia coli lactose operon by the Lac repressor provides the classical paradigm for this kind of control (Miller-Hill 1996). However, substrate-dependent control of gene expression can also be achieved after the initiation of transcription by a variety of mechanisms, including transcriptional attenuation, translational control, and modulation of mRNA decay.

Organisms often encounter in their habitats a mixture of different carbon sources and therefore possess means to selectively take up and metabolize those substrates that permit the most rapid growth and promise the best success in competition with other species. Many heterotrophic bacteria and fungi prefer glucose as a carbon source, and usually repress the use of other sugars when glucose is available. This phenomenon of "catabolite repression" relies on sensing of the activities of carbohy-

[Keywords: Small RNA; noncoding RNA; Hfq; RNase E; sugar; polyadenylation]

${ }^{3}$ Corresponding author.

E-MAIL vogel@mpiib-berlin.mpg.de; FAX 49-30-28460-244.

Article is online at http://www.genesdev.org/cgi/doi/10.1101/gad.1717808. drate transporters or of intracellular glycolytic metabolites. These cues modulate the synthesis of intracellular signaling molecules such as cAMP, or the activity of protein kinases, which in turn control the activity of global regulatory proteins; e.g., Crp (cAMP receptor protein) in enteric bacteria or cAMP-controlled protein kinase A in eukaryotic cells (Deutscher 2008; Gancedo 2008; Görke and Stülke 2008).

Once inside the cell, carbohydrates enter a central metabolic pathway i.e., glycolysis, the pentose phosphate pathway, or the Krebs (TCA) cycle. Flux through these pathways must be tightly coordinated with all other processes in the cell to avoid deleterious accumulation or depletion of metabolites. Global regulators such as the Escherichia coli Cra protein coordinate the transcription of glycolytic and gluconeogenic genes (see Nanchen et al. 2008 and references therein), whereas the widespread family of CsrA/RsmA RNA-binding proteins control metabolic genes at the post-transcriptional level. Notably, the CsrA/RsmA-like proteins are commonly associated with antagonistic small RNAs-e.g., E. coli CsrB (Liu et al. 1997) - that control the pool of active regulator (Babitzke and Romeo 2007; Lapouge et al. 2008). Moreover, there is extensive regulation at the metabolic enzyme level; e.g., by allosteric regulation or phosphorylation (Bott 2007; Lomas-Lopez et al. 2007; Macek et al. 2007).

In this review, we focus on a novel class of post-transcriptional regulators of bacterial sugar pathways; i.e., small noncoding RNAs (sRNAs) that act on trans-encoded target mRNAs. To date, sRNA functions have been studied most extensively in Gram-negative species including E. coli and Salmonella, in which a variety of approaches (Vogel and Sharma 2005) have identified more than a hundred chromosomally encoded sRNAs. These molecules, which typically range from 50 to 250 nucleotides (nt) in length, have been known in bacteria since the early 1970s, but their prevalence and impact on various biological control processes have been appreciated only recently (Majdalani et al. 2005; Storz et al. 2005; Romby et al. 2006). Since many E. coli sRNAs are conserved in a wider range of species (Hershberg et al. 2003), their functional analysis is often predictive of physiological roles beyond this model organism. Recent examples include the discovery of $E$. coli RyhB sRNA 
(Massé and Gottesman 2002), whose general role in iron homeostasis is recapitulated in orthologous or paralogous sRNAs in distantly related organisms-e.g., Pseudomonas or Vibrio species (Wilderman et al. 2004; Davis et al. 2005)—or of GcvB sRNA, which is likely to control peptide and amino acid transporter expression in a vast range of bacteria (Urbanowski et al. 2000; Sharma et al. 2007).

We selected for review three sRNA-based circuits built around the E. coli Spot42, SgrS, or GlmYZ sRNAs (Fig. $1)$, which promote the differential expression of the $E$. coli galactose utilization operon, counteract the toxic effects of glucose-6-phosphate (G6P) accumulation in the cell, or feedback-control GlmS synthesis in amino sugar production, respectively. As will become apparent, the study of these molecules has discovered or recapitulated fundamental principles of noncoding RNA regulators and led to better understanding of the involvement of protein factors such as Hfq, RNase E, and poly(A) polymerase in post-transcriptional regulation. Whereas the above E. coli sRNAs are trans-encoded regulators, Grampositive bacteria have evolved a totally different mechanism of $g \operatorname{lm} S$ regulation. This noncoding RNA function, which involves a cis-encoded ribozyme that senses an amino sugar, is reviewed for comparison.

\section{The galETKM operon and its functions}

The E. coli galETKM operon encodes enzymes that convert galactose to the glycolytic intermediate glucose-1phosphate (Fig. 1). This pathway provides carbon and energy from the degradation of galactose and is also important for the synthesis of UDP-glucose and UDPgalactose, which are required for glycosylations; i.e., the biosynthesis of lipopolysaccharides.
The gal operon is expressed at a rather high level even in the absence of the operon-specific inducer galactose, allowing the cell to synthesize the UDP sugars from G6P. This anabolic pathway also generates galactose whose fate depends on the available carbon source. If it is glucose, the galactose is excreted, and therefore the GalK enzyme (encoded by the third gene in the operon) is idle. If there is no glucose, the cells recycle the intracellularly generated galactose in a GalK-dependent manner. To match the differential need of GalK, the gal operon proteins are differentially synthesized depending on the physiological condition (Wilson and Hogness 1969). That is, the presence of glucose decreases GalK synthesis by fourfold relative to the other Gal proteins, whereas normally equimolar amounts of all four Gal operon proteins are produced when glucose is absent. The underlying mechanism remained obscure until the discovery of Spot42 RNA action in this pathway.

\section{Spot42 regulates galK translation within the galETKM operon mRNA}

Spot42 has been somewhat of a veteran of the small RNA field; it was first encountered in the 1970s as an abundant RNA species ( 200 copies per cell) by two-dimensional gel electrophoresis of metabolically labeled $E$. coli RNA (Ikemura and Dahlberg 1973). The spf (spot forty-two) gene encoding this 109-nt RNA (Fig. 2A) was subsequently identified in the polA-yihA intergenic region (Rice and Dahlberg 1982). There was a considerable amount of early work to define a Spot42 function. For example, whereas deletion of spf failed to produce an obvious phenotype (Hatfull and Joyce 1986), overproduction of the RNA increased the generation time of bacteria grown on succinate, resulted in smaller colony size,

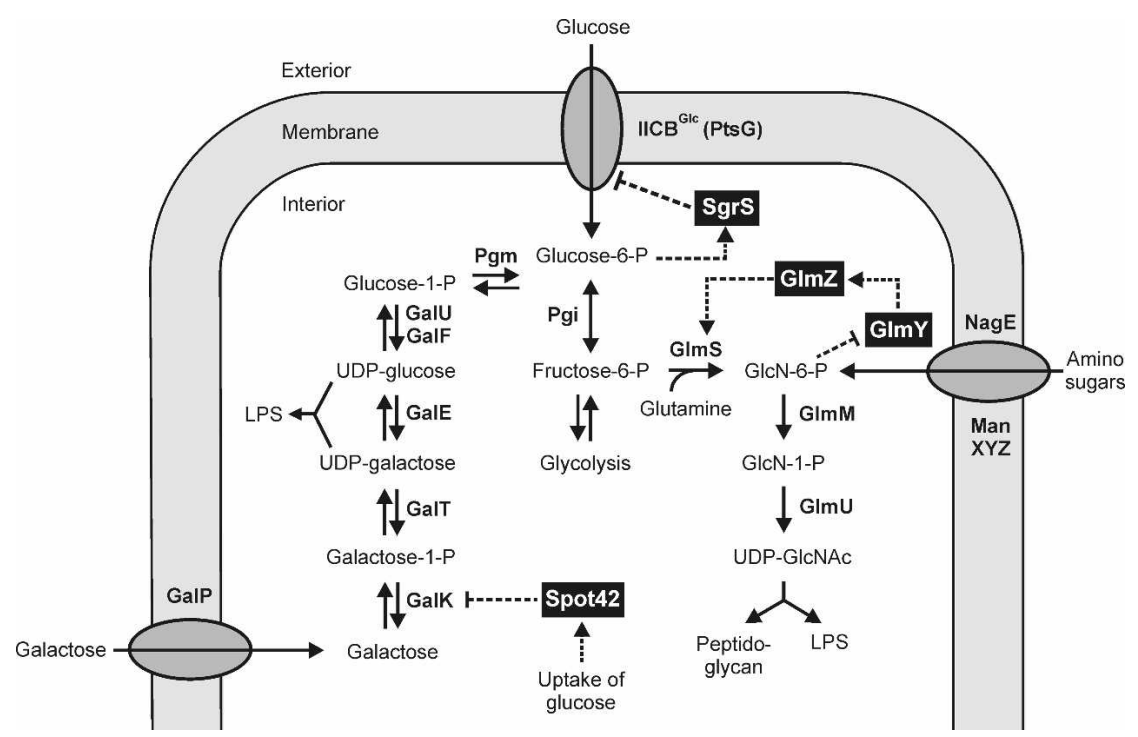

Figure 1. Central carbohydrate metabolic pathways controlled by small RNAs for uptake and metabolism of galactose, glucose, and amino sugars. These pathways also have important anabolic functions as they are required for the biosynthesis of lipopolysaccharides (LPS) of the outer membrane and/or the bacterial cell wall. Spot42 sRNA controls the synthesis of the galactokinase $(\mathrm{GalK})$ in response to the availability of glucose in the environment. SgrS sRNA represses the synthesis of the glucose transporter EII ${ }^{\mathrm{Glc}}$ and prevents the further uptake of glucose when G6P accumulates to toxic levels. The GlmYZ sRNAs feedback-control the expression of glucosamine-6-phosphate synthetase (GlmS) in response to its product, GlcN-6P. Enzymes and transporters are depicted in bold. (GalP) Galactose transporter; (GalT) uridyltransferase; (GalE) UDP-glu-

cose epimerase; (GalF and GalU) subunits of the glucose-1-phosphate uridylyltransferase; (Pgm) phosphoglucomutase; (Pgi) phosphoglucose isomerase; (GlmM) phosphoglucosamine mutase; (GlmU) N-acetylglucosamine-1-phosphate uridyltransferase; (NagE) N-acetylglucosamine PTS transporter; (ManXYZ) mannose PTS transporter; (UDP) uridine diphosphate; (GlcN-1-P) glucosamine-1-phosphate; (GlcNAc) N-acetylglucosamine. 
A

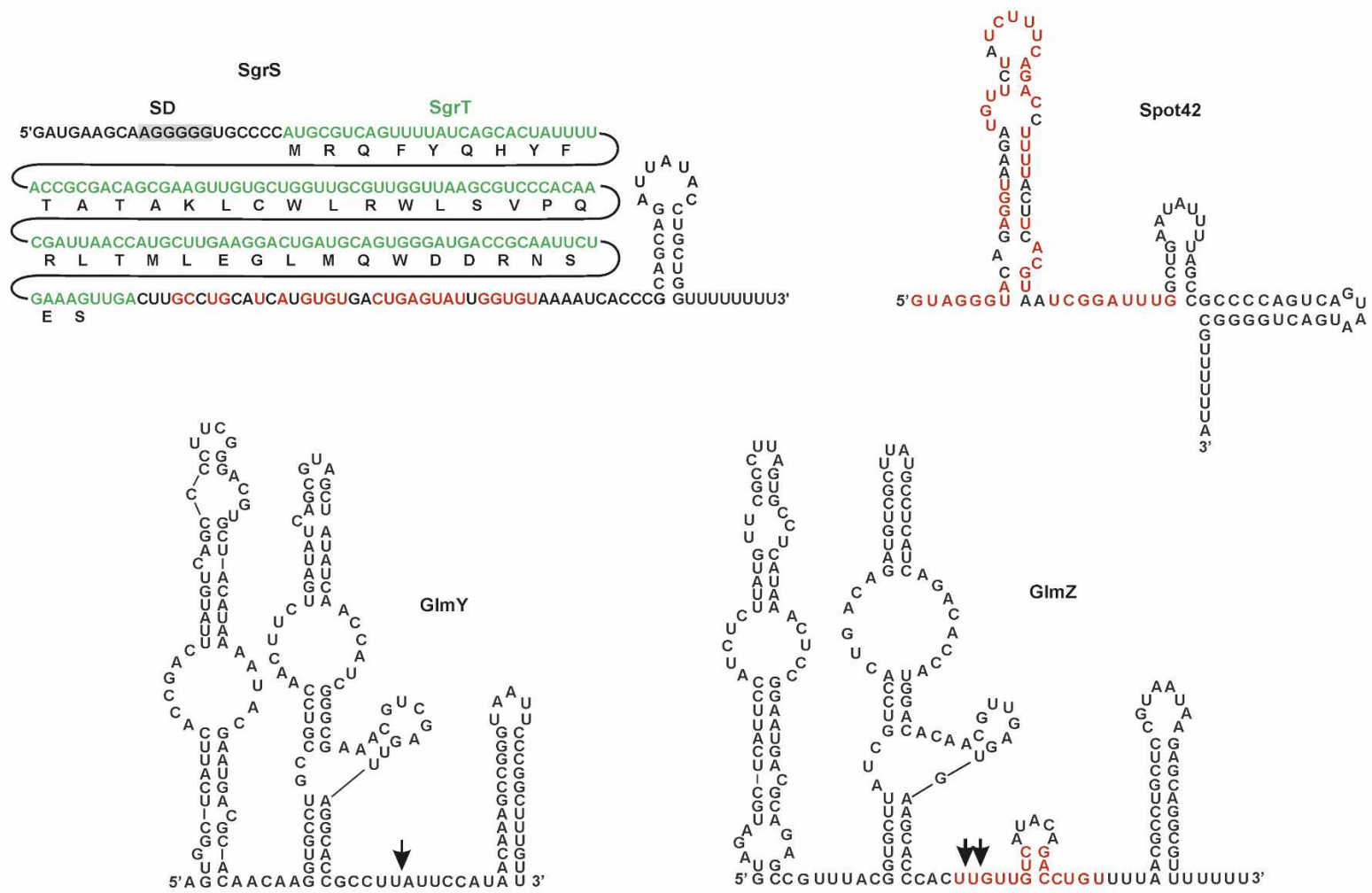

B

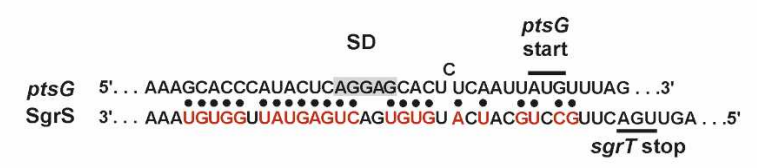

sgrT stop

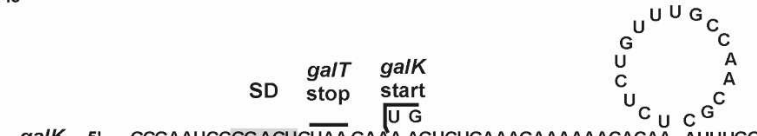

galk $5{ }^{\prime} \ldots$ GCGAAUCCGG AGUGUAA GAAA AGUCUGAAAGAAAAAACACAA AUUUGGCUACCCUGC $\ldots 3^{\prime}$

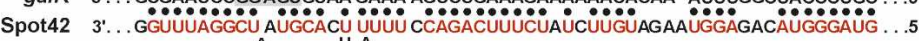

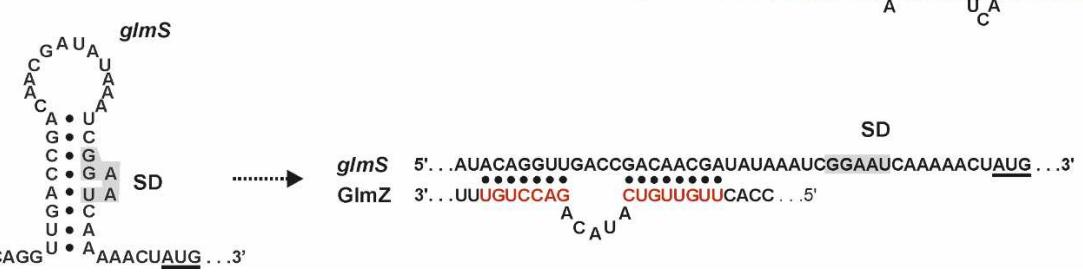

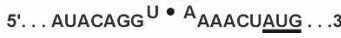

Figure 2. Small RNAs controlling bacterial sugar pathways. (A) Secondary structures of Spot42, GlmY, and GlmZ sRNAs as predicted by structural probing or by Mfold software analysis (note that the secondary structure of SgrS is unknown). sRNA residues that pair with target mRNAs are highlighted in red. The sgrT ORF in SgrS is highlighted in green. Previously mapped processing sites in $G \operatorname{lmY} / Z$ are indicated by vertical arrows. $(B)$ Pairing of sRNAs with their target mRNAs according to computational and experimental analysis. The relevant portions of the RNAs are shown. Shine-Dalgarno (SD) sequences are highlighted by gray boxes, and start/stop codons underlined. Base-pairing is indicated by black dots. (Bottom left) The stem-loop that sequesters the glmS SD in the absence of active GlmZ is shown for comparison.

and impaired the adaptation to changes in media composition (Rice and Dahlberg 1982). While the early studies fell short of defining a physiological role, they did suggest that Spot42 was likely a regulatory RNA (Rice et al. 1987).

The mystery of Spot42 function was solved when Val- 
entin-Hansen and coworkers (Møller et al. 2002b) noticed that Spot42 exhibited significant complementarity to the galK start codon region. The inverse correlation of $s p f$ and galK expression in response to glucose prompted them to pursue the galETKM mRNA as a potential antisense target (Møller et al. 2002b). That is, the spf gene is subject to repression by the cAMP-CRP complex (Sahagan and Dahlberg 1979; Polayes et al. 1988), which reduces Spot42 levels threefold to fivefold in the absence of glucose; concomitantly, the glucose-dependent fourfold repression of GalK synthesis is alleviated. It was demonstrated that the sRNA selectively inhibits the synthesis of GalK but not of the GalE and GalT proteins encoded upstream in the gal operon mRNA (Fig. 3A; Møller et al. 2002b).

Spot42 specifically binds to the $5^{\prime}$ part of the galK mRNA and acts as a translational inhibitor that prevents $30 \mathrm{~S}$ ribosome binding to the galK moiety of the operon mRNA. Probing of the Spot42-galK mRNA complex identified three predominantly single-stranded regions in Spot42 RNA that antisense-paired with the AUG region of galK mRNA (Fig. 2B). The target site overlaps with the $3^{\prime}$ end of the galT, thus Spot42 binding must withstand the helicase activity of a ribosome elongating along the upstream galT gene. The selective repression of GalK synthesis by Spot 42 established a novel principle in bacterial gene regulation; i.e., the intraoperonic targeting of a gene at the post-transcriptional level (Fig. 3).

\section{A crucial role of Hfq protein in Spot42-target RNA interaction}

Similar to many other sRNAs (see below), the pairing of Spot42 with its target galK is imperfect and discontinuous. How is efficient base-pairing accomplished? It was known at the time that the bacterial Sm-like protein Hfq interacted with several E. coli sRNAs, and that its presence is required for regulation in vivo (Zhang et al. 1998; Sledjeski et al. 2001; Wassarman et al. 2001). Spot42
RNA was also found to be associated with Hfq protein in vivo, and Hfq was shown to target three short singlestranded A/U-rich regions of the sRNA (Møller et al. 2002a). Interestingly, these binding motifs resembled those of eukaryotic Sm proteins, which are involved in various aspects of RNA regulation and metabolism. Moreover, the homohexameric Hfq protein was shown to form ring-like doughnut-shaped structures reminiscent of the oligomeric structures of Sm proteins. Structural analyses unequivocally confirmed that $\mathrm{Hfq}$ is an Sm homolog (Brennan and Link 2007). One Hfq hexamer binds a Spot42 molecule, and Hfq increases the interaction of Spot42 with its galK target RNA by 150 -fold, resulting in a tripartite ribonucleoprotein (RNP) complex composed of the regulatory RNA, its target, and Hfq. These findings, together with parallel work on Hfq and OxyS sRNA by the Storz laboratory (Zhang et al. $1998,2002)$, laid the ground for the meanwhile fully appreciated role of $\mathrm{Hfq}$ as a key facilitator of sRNA-mRNA interactions.

\section{SgrS RNA combats phosphosugar stress}

Many bacteria take up glucose by the phosphoenolpyruvate phosphotransferase system (PTS) (Plumbridge 2002; Deutscher et al. 2006). PTS enzyme IICB ${ }^{\text {Glc }}$, encoded by $p t s G$ in E. coli, is a key player in this process; it transports and concomitantly phosphorylates glucose to G6P. While G6P is an essential intermediate in glucose metabolism, its intracellular accumulation causes the phenomenon of sugar-phosphate toxicity, also called "phosphosugar stress." The Aiba laboratory made the seminal observation that this stress condition destabilizes the $p t s G$ mRNA, thereby limiting enzyme $\mathrm{IICB}^{\mathrm{Glc}}$ synthesis and further G6P accumulation (Kimata et al. 2001). Intriguingly, this post-transcriptional repression of $p t s G$ required Hfq (Morita et al. 2004), indicative of the hidden action of an sRNA.

The sRNA to combat phosphosugar stress in E. coli
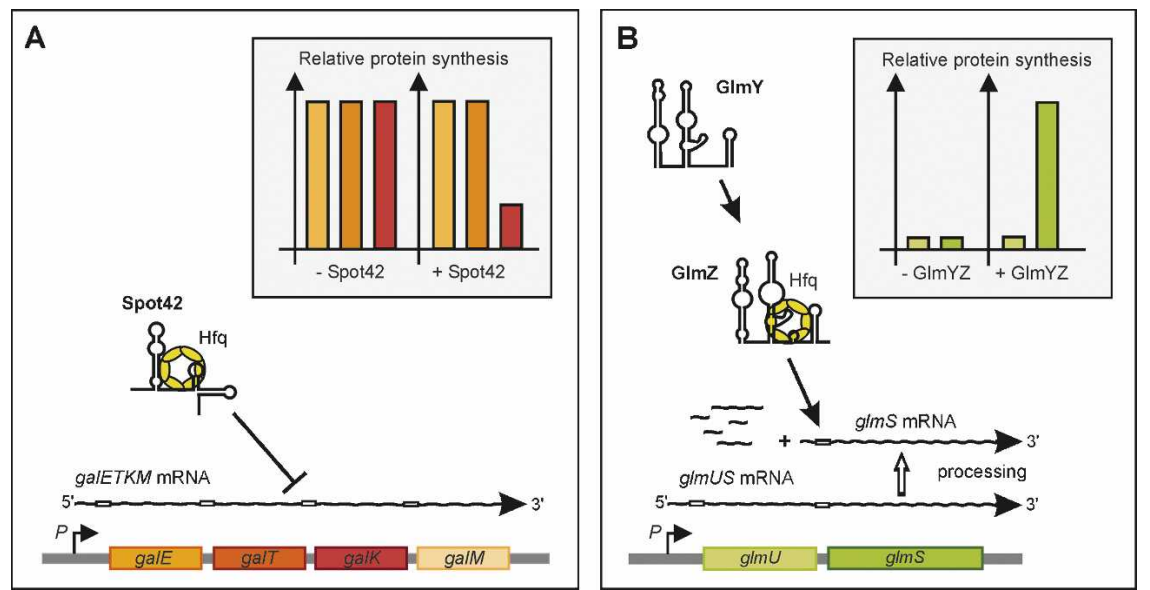

Figure 3. Intraoperonic targeting by sRNAs as a novel principle in gene regulation that permits the selective regulation of a downstream cistron within a polycistronic messenger in response to a specific signal. (A) Spot42 sRNA selectively represses galK translation within the polycistronic galETKM mRNA. (Top) Aided by Hfq, Spot42 binds to the translation initiation region of galK and reduces synthesis of the GalK protein threefold to fourfold, whereas synthesis of the GalE and GalT proteins remains unaffected. $(B)$ Following transcription, the $g \operatorname{lm} U S$ cotranscript is processed by RNase $\mathrm{E}$ at the $g \operatorname{lm} U$ stop codon. Whereas the $\operatorname{glm} U$ message is rapidly degraded, the $\operatorname{glm} S$ monocistronic transcript can be stabilized by Hfq-aided base-pairing with the GlmZ sRNA. GlmZ binds to the 5' UTR of the $g \operatorname{lm} S$ mRNA and removes a translational block allowing high GlmS synthesis rates. The homologous GlmY sRNA accumulates in response to depletion of the intracellular GlcN6P concentration and activates $\operatorname{glm} S$ indirectly by suppressing the endonucleolytic inactivation of GlmZ sRNA. 
was identified as SgrS by Vanderpool and Gottesman (2004), an sRNA originally discovered by global microarray analysis of Hfq-asscociated RNA (Zhang et al. 2003). Induced SgrS expression from a plasmid caused a rapid loss of the ptsG messenger, and reciprocally, deletion of the $\operatorname{sgr} S$ gene abrogated the $p t s G$ down-regulation that normally follows phosphosugar stress /Vanderpool and Gottesman 2004). With a length of $220 \mathrm{nt}$, E. coli SgrS is at the longer end of the enterobacterial sRNA size range (Fig. 2A). This reflects the fact that SgrS also encodes a polypeptide (see below). SgrS is transcribed from the intergenic region that separates $\operatorname{sgr} R$ and $\operatorname{set} A$, two genes that directly or indirectly relate to $\mathrm{SgrS}$ action.

Phosphosugar stress-induction of $\operatorname{sgrS}$ requires the adjacently encoded SgrR protein, a novel type of transcriptional regulator, and based on genetic and molecular evidence, SgrR is now regarded as a dedicated transcriptional activator of $\operatorname{sgrS}$ (Vanderpool 2007). Genomic linkage of an sRNA gene ( $g g r S)$ with its cognate transcription factor $(\operatorname{sgr} R)$ gene has been a recurring theme in E. coli; e.g., gcvB and oxyS are also next to (and divergent from) the genes of their transcriptional factors (Altuvia et al. 1997; Urbanowski et al. 2000).

\section{SgrS targets ptsG mRNA by short antisense pairing}

The observations that SgrS is Hfq-associated (Zhang et al. 2003) and that Hfq is mandatory for stress-induced pts $G$ repression (Morita et al. 2004) correctly predicted that SgrS regulation relies on an antisense mechanism. The SgrS-ptsG interaction, initially proposed by Vanderpool and Gottesman (2004), was extensively studied by Aiba and colleagues (Kawamoto et al. 2005, 2006). As depicted in Figure 2B, residues 168-187 of SgrS pair with the $5^{\prime}$ untranslated region (UTR) of pts $G$ mRNA around the SD sequence, forming an imperfect 20-base-pair (bp) RNA duplex that contains several $\mathrm{C}: \mathrm{U}$ or A:G mismatches. The detailed genetic evidence available (Kawamoto et al. 2006) makes the SgrS-ptsG interaction attractive for further RNA structure analysis. Work on several sRNAs unrelated to sugar control circuits revealed that the interacting residues are often presented by distinct structural elements-e.g., apical loop regions (Argaman and Altuvia 2000; Boisset et al. 2007; Papenfort et al. 2008) —and this quite mirrors the mechanisms of target recognition by cis-encoded antisense RNAs (Wagner et al. 2002).

Alignment of the predicted SgrS RNAs of diverse bacteria reveals great sequence diversity, but the $p t s G$ pairing site is visible as a short conserved region /Vanderpool and Gottesman 2004). Given the considerable length of bacterial sRNAs, on the one hand, and short imperfect mRNA interactions, on the other hand, reliable sRNA target predictions have remained a challenge. Yet exploiting the conservation of "antisense domains" containing the target mRNA-binding site(s), such as seen in SgrS, should improve target predictions; it has already aided the identification of binding sites of the $\sim 200-n t$ GcvB sRNA on multiple ABC transporter target mRNAs (Sharma et al. 2007).

\section{Concerted action of Hfq and RNase E}

Rapid loss of ptsG mRNA is the most apparent outcome in the phosphosugar stress response (Kimata et al. 2001; Vanderpool and Gottesman 2004). However, SgrS pairing covers the SD sequence of ptsG mRNA (Fig. 2B), indicating that it could also inhibit ptsG translation. Since the half-life of bacterial mRNA is strongly affected by the association with ribosomes (Deana and Belasco 2005), one may infer a simple model in which ptsG mRNA decay stems from an SgrS-mediated translation block. Yet, there is more than one layer of SgrS action, and this includes a novel ribonucleoprotein complex (RNP) essential for ptsG mRNA decay.

This novel RNP is composed of RNase E, Hfq, and SgrS (Morita et al. 2005), but might as well form with other Hfq-dependent sRNAs (Massé and Gottesman 2002; Morita et al. 2005). RNase E, the major ribonuclease of $E$. coli, is typically found in the "degradosome," a complex assembled by PNPase, RhlB, and enolase binding to the C-terminal "scaffold" region of RNase E (Carpousis 2007). Strikingly, whereas RNase E including its scaffold region was essential for stress-induced $p t s G$ mRNA decay, other degradosome components did not seemed to be required (Morita et al. 2005). Analysis of the proteins that copurified with epitope-tagged RNase E, Hfq, or $\mathrm{RhlB}$ indicated that $\mathrm{Hfq}$ interacted with the RNase E scaffold independently of degradosome assembly. This association recruits the Hfq-associated SgrS sRNA to RNase E, and SgrS can then direct RNase E/Hfq to the ptsG target (Morita et al. 2005). Thus, Hfq has dual function: It facilitates stable SgrS-ptsG pairing (Kawamoto et al. 2006) and hands the regulatory RNAs a nucleolytic cofactor that will irreversibly inactivate the target. If Hfq and RNase E are always in a complex, this poses the intriguing question why other sRNA targets are repressed without concomitant mRNA decay. For example, Spot42 does not seem to recruit RNase E to the gal operon mRNA albeit it is tightly associated with Hfq. However, recent work from the Luisi laboratory (Worrall et al. 2008) suggested that the RNase E-Hfq interaction may not be direct but may be brought about by RNA; if so, not all regulatory sRNAs may be able to bring the two proteins into a complex.

The association of SgrS with RNase E could also provide an anticipatory control mechanism that allows the cell to rapidly reverse the down-regulation of $p t s G$ when phosphosugar stress is lifted. Massé et al. (2003) demonstrated by elegant in vivo experiments that several Hfqdependent sRNAs decay along with their targets in an RNase E-dependent fashion. In the absence of target pairing, Hfq may protect the sRNAs from RNase E, but upon target pairing, both the mRNA and the sRNA become labile (Massé et al. 2003). Since RNase E and Hfq have coincident binding sites (single-stranded A/U-rich regions) (Moll et al. 2003), RNase E presumably displaces Hfq on its RNA targets.

Targeted mRNA destabilization turned out to be just one side of the SgrS story. In an RNase E mutant strain defective in ptsG mRNA decay, SgrS still reduced the 
levels of the ptsG-encoded IICB ${ }^{\text {Glc }}$ protein (Morita et al. 2006). Metabolic protein labeling immediately after phosphosugar stress induction showed that SgrS inhibited IICB ${ }^{\text {Glc }}$ protein synthesis in vivo without concomitant target mRNA destruction (Morita et al. 2006). Moreover, following earlier assays of sRNA-induced inhibition of translational initiation using 30S ribosomese.g., for OxyS/fhlA mRNA (Altuvia et al. 1998)—it has now been demonstrated that SgrS by itself can inhibit pts $G$ mRNA translation in a reconstituted in vitro translation system (Maki et al. 2008). In more general terms, this translational repression mechanism is in striking contrast to the function of eukaryotic microRNAs, which achieve target repression by the recruitment of dedicated proteins and only function to select the correct mRNA.

\section{mRNA localization matters}

The nascent ptsG mRNA will first be cytoplasmic but later on near the membrane as the $\mathrm{IICB}^{\mathrm{Glc}}$ protein will be cotranslationally integrated into the inner membrane. Kawamoto et al. (2005) made the crucial observation that SgrS action on ptsG mRNA is strictly dependent on intact protein localization. The investigators discuss several models of why membrane-localized but not cytoplasmic ptsG mRNA is an SgrS target, including the accumulation of RNase E near the membrane (Liou et al. 2001) and a reduced translational initiation rate during the course of cotranslational integration of the nascent peptide into the membrane. Note that since most bacterial sRNAs can be expected to act on nascent target mRNAs, competition between sRNA pairing and ribosome binding is very likely a general principle (Unoson and Wagner 2007). In line with this model, SgrS could regulate pts $G$ mRNA regardless of membrane localization when the ptsG translation rate was artificially reduced (by a weaker SD sequence) (Kawamoto et al. 2005). We have yet to see to what extent mRNA localization matters in sRNA circuits. Interestingly, another SgrS target-i.e., manXYZ mRNA-seems to be regulated independently of mRNA localization (C. Vanderpool, pers. comm.). However, given that many sRNA targets encode extracytoplasmic proteins-e.g., outer membrane, periplasmic, or secreted proteins (Guillier et al. 2006; Vogel and Papenfort 2006; Boisset et al. 2007; Sharma et al. 2007)—spatial control may not be uncommon.

\section{SgrS action taken beyond antisense regulation}

Strictly speaking, SgrS is not a "noncoding" but a bifunctional RNA that is both antisense regulator and mRNA. Wadler and Vanderpool (2007) discovered that in the long $5^{\prime}$ region upstream of the $p t s G$ interaction site there is a conserved 43-amino-acid ORF, named $\operatorname{sgrT}$ (Fig. 2A). The SgrT peptide and ptsG base-pairing are equally sufficient to protect $E$. coli from phosphosugar stress, suggesting physiological redundancy. By a yet-unknown mechanism, SgrT may antagonize the preexisting $\mathrm{IICB}^{\mathrm{Glc}}$ pro- tein, while the pairing of SgrS with ptsG blocks ongoing IICB $^{\text {Glc }}$ synthesis (Wadler and Vanderpool 2007).

Dual functionality has been known for the 514-nt RNA III of Staphylococcus aureus, whose 5' end codes for a short virulence peptide, whereas the $3^{\prime}$-end-located antisense domain regulates a multitude of virulence factor mRNAs (Novick et al. 1993; Huntzinger et al. 2005; Boisset et al. 2007). It will be interesting to understand how such RNAs can control trans-encoded mRNAs if they are also ribosome targets.

The sgrS gene may hold more surprises owing to its location right upstream of the set $A B C$ operon (Vanderpool and Gottesman 2004). The SetABC proteins belong to a family of sugar efflux transporters, and SetA has broad substrate specificity including glucosides (Liu et al. 1999). The sgrS terminator lies only $\sim 25$ bp upstream of the setA start codon (Vanderpool and Gottesman 2004), and read-through transcripts from sgrS may also activate the set $A B C$-encoded sugar efflux pump when elevated G6P levels become a threat. If so, this cis effect would be yet another novel function of this exciting sRNA gene.

\section{Intraoperonic gene targeting the other way around: the GImYZ sRNAs activate a downstream cistron}

We discussed that Spot42 modulates the expression of the galETKM operon by selective repression of a downstream cistron. The opposite case-i.e., the selective activation of a downstream cistron by sRNA-leads to differential expression of E. coli glmUS mRNA. This operon encodes enzymes of the biosynthetic pathway for amino sugars, which are essential precursors for the peptidoglycan and lipopolysaccharide components of the cell wall of Gram-negative bacteria (Fig. 1). Whereas GlmU is constantly needed, GlmS only becomes essential for the synthesis of glucosamine-6-phosphate (GlcN6-P) when no external amino sugars are available. Owing to strict transcriptional coupling of the glmUS genes (Plumbridge 1995), the relative synthesis of GlmS in response to substrate availability can only be adjusted after transcription (Fig. 3B). Although RNase E-dependent processing was shown to generate a monocistronic $\mathrm{g} \operatorname{lm} S$ from the dicistronic glmUS mRNA (Joanny et al. 2007; Kalamorz et al. 2007), there was no evidence that the cleavage was metabolically regulated. In contrast, independent studies from our two laboratoriess recently identified two E. coli sRNAs, GlmY and GlmZ (Fig. 2 A), as suboperonic stimulators of GlmS synthesis (Kalamorz et al. 2007; Urban et al. 2007; Reichenbach et al. 2008; Urban and Vogel 2008).

The GlmY and GlmZ sRNAs were originally described in multiple E. coli screens (Argaman et al. 2001; Rivas et al. 2001; Wassarman et al. 2001; Vogel et al. 2003), yet their now obvious functional and structural relationship was not realized before each of them was revealed as an activator of GlmS synthesis. Overexpression of GlmY caused such drastic GlmS accumulation that this protein became readily visible on standard SDS gels; the levels of the upstream encoded GlmU protein, however, were un- 
affected (Urban et al. 2007). In parallel, a transposon screen discovered the $g \operatorname{lm} Z$ gene as the cause of chronic GlmS overproduction in a certain $E$. coli mutant (yhbJ; see below); again, only GlmS and not GlmU levels were altered (Kalamorz et al. 2007). Note that the latter study constitutes a rare case in which a transposon mutagenesis screen led to the recognition of an sRNA's function, whereas sRNA overexpression was the typical route to success (Vogel and Wagner 2007).

The two sRNAs are highly similar in length, sequence, and structure (Fig. 2A). Yet these seemingly homologous sRNAs activate GlmS synthesis by entirely different mechanisms and act hierarchically in a noncoding RNA cascade.

\section{Mechanism of translational activation by bacterial sRNAs}

Translation of the $g \operatorname{lm} S$ mRNA is normally weak since an internal hairpin structure containing the $g \operatorname{lm} S$ SD sequence (Fig. 2B) limits ribosome access to the downstream $\operatorname{glm} S$ RBS and therefore GlmS synthesis. This situation is reminiscent of rpoS mRNA control in E. coli $\left(r p o S\right.$ encodes the general stress sigma factor, $\left.\sigma^{\mathrm{S}}\right)$ : Translation of this messenger is normally low owing to an intrinsic RBS hairpin. Yet, rpoS translation can be activated by the trans-encoded DsrA and RprA sRNAs via an "anti-antisense" mechanism; base-pairing of these sRNAs with the rpoS mRNA leader competes with the formation of the inhibitory RBS hairpin, thus promoting translation (Lease et al. 1998; Majdalani et al. 1998, 2002).

In silico analysis (Kalamorz et al. 2007) and RNA structure probing experiments (Urban and Vogel 2008) indicated the same mechanism for $g 1 m S$ mRNA: Some 15 residues of an accessible, single-stranded region of GlmZ RNA base-pair with the 5' flank of the glmS RBS hairpin (Fig. 2B); this alternative pairing liberates the SD and activates $g \operatorname{lm} S$ mRNA translation. Mutational analyses in vivo support this interaction; point mutations in the upper and lower helices of the GlmZ-glmS interaction abrogate $g \mathrm{~lm} S$ induction, but when combined in a compensatory fashion, activation by GlmZ is restored (Urban and Vogel 2008). In addition, the $\operatorname{glm} S$ mRNA activation by GlmZ has also been recapitulated in an in vitro translation system (Urban and Vogel 2008). This illustrates that the anti-antisense mechanism in essence requires only the translational machinery and an activator sRNA. Following its encounter in other bacterial sRNA circuits (Hammer and Bassler 2007; Prevost et al. 2007), the anti-antisense mechanism is now regarded as the paradigm of sRNA-mediated mRNA activation.

Note, however, that in vivo GlmZ not only enhances $\operatorname{glm} S$ translation but also stabilizes this mRNA (Kalamorz et al. 2007; Urban and Vogel 2008). Whether the increase in mRNA translation and stability is directly coupled remains to be determined. In vitro the addition of purified Hfq protein increases the effect of GlmZ on translation by almost 10-fold (Urban and Vogel 2008), and in vivo, Hfq is ultimately required for glms activa- tion (Kalamorz et al. 2007; Urban and Vogel 2008). In vivo Hfq not only associates with the GlmY or GlmZ sRNAs (Zhang et al. 2003; Sittka et al. 2008) but also specifically with the glmUS intergenic region (Sittka et al. 2008), in line with Hfq's common function as a matchmaker of sRNA-target mRNA interactions.

\section{A regulatory RNA cascade-GlmY acts on $G \operatorname{lmZ}$ to activate GlmS synthesis}

GlmY and GlmZ look much alike, yet GlmY lacks the residues of GlmZ that target the glmS hairpin (Fig. 2A) and also fails to promote GlmS synthesis in vitro (Urban and Vogel 2008). How can it then activate the $g \operatorname{lm} S$ gene in vivo? It does so by counteracting the inactivation of GlmZ.

The primary 207-nt GlmZ transcript is subject to a 3 '-RNA processing that involves the action of YhbJ, a conserved protein of as-yet-unknown function (Kalamorz et al. 2007). The processing generates a 153-nt GlmZ species (Argaman et al. 2001) that is deprived of the $\operatorname{glm} S$-binding site and does not promote GlmS synthesis in vitro (Urban and Vogel 2008). By a yet-unknown mechanism, GlmY antagonizes the deleterious GlmZ processing and thereby increases the levels of the direct glmS activator (Reichenbach et al. 2008; Urban and Vogel 2008). This antagonism may involve RNA mimicry of GlmY to compete with the factor(s) that tag the highly similar GlmZ RNA for cleavage.

Families of homologous sRNAs have been reported from diverse bacteria other than E. coli; e.g., Vibrio, Pseudomonas, and cyanobacterial species (Lenz et al. 2004; Wilderman et al. 2004; Axmann et al. 2005; Lapouge et al. 2008). Where known, these sRNAs act redundantly and/or additively, and to some degree substitute for each other's function. In contrast, the hierarchical action of the GlmYZ sRNAs is novel such that GlmY strictly requires GlmZ for $g \operatorname{lm} S$ activation (Reichenbach et al. 2008; Urban and Vogel 2008).

\section{Polyadenylation controls sRNA expression}

Hfq and YhbJ take decisive roles in the GlmYZ cascade by controlling GlmZ activity at the RNA level (Kalamorz et al. 2007; Urban and Vogel 2008). Yet another protein regulates GlmY levels, and again at the posttranscriptional level; it is the main enzyme responsible for $3^{\prime}$-end RNA polyadenylation, PAP I [poly(A) polymerase I encoded by $p c n B$ ] (Cao and Sarkar 1992).

Historically, PAP I was the first factor implicated in post-transcriptional $g \operatorname{lm} S$ regulation when the study of an $E$. coli $p c n B$ mutant revealed chronic overproduction of both glmS mRNA and GlmS protein (Joanny et al. 2007). Since poly(A) tails typically destabilize bacterial transcripts by accelerating the $3^{\prime} \rightarrow 5^{\prime}$ exonucleolytic degradation of RNA (Dreyfus and Regnier 2002; Kushner 2004), it was speculated that the loss of polyadenylation directly impeded the decay of glmS mRNA (Joanny et al. 2007). However, the observations that $g \operatorname{lm} S$ reporter fu- 
sions with $3^{\prime}$ ends different from native glmS mRNA, as well as that the GlmYZ sRNAs were also up-regulated in the PAP I-deficient strain $(p c n B \Delta 1)$, hinted at a different mechanism (Kalamorz et al. 2007; Reichenbach et al. 2008; Urban and Vogel 2008). Assessment of the stability and the poly(A) status of the GlmY, GlmZ, or $g \operatorname{lm} S$ RNAs revealed that GlmY was the only RNA for which differential stabilities and expression levels in $p c n B \Delta 1$ cells correlated with the presence or absence of 3 '-end poly(A) tails. Thus, if GlmY is no longer polyadenylated (normally $>50 \%$ of all GlmY molecules), it is stabilized and accumulates, which in turn stabilizes GlmZ and increases glmS translation (Reichenbach et al. 2008; Urban and Vogel 2008).

Polyadenylation-dependent destabilization had for long been known to affect cis-encoded antisense RNAs of bacterial plasmids (Xu et al. 1993; Dam Mikkelsen and Gerdes 1997; Söderbom et al. 1997), yet GlmY was the first chromosomal sRNA whose polyadenylation impacts on the synthesis of a cellular protein.

\section{Multiple input functions in sRNA-mediated amino sugar regulation}

The analyses of the GlmYZ RNAs solved the long-standing puzzle of how GlmS activity, which is feedback-inhibited at the enzyme level in eukaryotic systems (Milewski 2002) and cis-controlled in Gram-positive bacteria (Winkler et al. 2004), was autoregulated in Gramnegative bacteria. Physiological studies using various inhibitors of amino sugar and cell wall synthesis pathways demonstrated that the GlmYZ RNAs are essential for feedback control of E. coli GlmS synthesis by its product, GlcN6P. Depletion of GlcN6P causes the accumulation of GlmY, which induces GlmS synthesis by stabilizing GlmZ (Kalamorz et al. 2007; Reichenbach et al. 2008).

It will now be important to understand how this RNA cascade senses the environmental signals that determine $\operatorname{glm} S$ epistasis. Moreover, the precise mechanism of how YhbJ affects GlmZ RNA processing is yet to be solved. The protein, which is conserved in many bacteria, contains a nucleotide-binding motif, and software analysis predicts a putative RNA-binding domain at the C terminus. Regardless of the precise molecular mode of action, the unexpected discovery of YhbJ as a mediator of sRNA processing hints at the existence of additional proteins that modulate the activity of regulatory sRNAs.

\section{Regulation of glmS expression by a ribozyme in Gram-positive bacteria}

In low GC Gram-positive bacteria, glmS expression is also regulated at the post-transcriptional level yet by a cis-encoded ribozyme (Winkler et al. 2004) rather than trans-encoded sRNAs. The $g \mathrm{~lm} S$ ribozyme was discovered during a biocomputational search for conserved sequence and structural elements in unusually large intergenic regions of bacterial genomes (Barrick et al. 2004). The ribozyme resides in the 5' UTR of the $g \operatorname{lm} S$ mRNA.
Unlike classical riboswitches, it lacks a transcriptional or translational attenuator. In contrast, in vitro experiments showed that it undergoes self-cleavage specifically in the presence of GlcN6P (Winkler et al. 2004).

In the in vivo situation, this cleavage event liberates the $g \operatorname{lm} S$ mRNA from a larger polycistronic transcript (Winkler et al. 2004) and down-regulates GlmS synthesis. The Winkler lab has deciphered the in vivo mechanism of gene regulation by the Bacillus subtilis ribozyme (Collins et al. 2007). By altering the intracellular GlcN6P concentration, they showed that GlcN6P depletion highly up-regulated $\operatorname{glm} S$ expression. Under this condition, the uncleaved full-length $g \operatorname{lm} S$ transcript accumulated, whereas no $g \operatorname{lm} S$ transcript was detectable in the presence of high GlcN6P concentrations. Mutations in the ribozyme that prevent cleavage also cause accumulation of the full-length glmS mRNA, regardless of the GlcN6P concentration. RNase J1, an essential nuclease with a key role in RNA processing and degradation in B. subtilis (Even et al. 2005; Mathy et al. 2007), was subsequently identified as the enzyme that is responsible for the rapid degradation of the 3 ' cleavage product of the ribozyme (Collins et al. 2007).

Cleavage of the $\operatorname{glm} S$ ribozyme was shown to occur by an internal phosphoester transfer yielding products with 2 ', 3 '-cyclic phosphate and 5 ' hydroxyl moieties at the termini (Winkler et al. 2004; Collins et al. 2007). RNase J1 specifically degrades RNAs with a 5' hydroxyl group, which is radically different from the paradigmatic model of global mRNA decay in E. coli, in which the unrelated enzyme RNase E specifically recognizes $5^{\prime}$ monophosphate mRNA, whereas $5^{\prime}$ hydroxyl RNA is stable (Celesnik et al. 2007). There is accumulating evidence that Gram-positive and Gram-negative bacteria evolved completely different RNA decay mechanisms.

\section{The unique features of the glmS ribozyme}

Among the known metabolite-sensing RNAs in nature, the one in $\operatorname{glm} S$ is unique because it represents the only ribozyme so far that controls gene expression, and because its ligand GlcN6P is a cofactor in the underlying acid-based catalysis of RNA self-cleavage. The $g \operatorname{lm} S$ ribozyme has become a model RNA for biochemical and biophysical studies, including the determination of its crystal structures, alone or in complex with GlcN6P (Klein and Ferre-D'Amare 2006; Cochrane et al. 2007). Collectively, these studies demonstrated that unlike in classical riboswitches, no conformational changes occur in the ribozyme upon GlcN6P binding and RNA cleavage. A recent study demonstrated that the ribozyme can be physically separated from its target RNA without losing activity (Tinsley et al. 2007); if an engineered $\mathrm{g} \operatorname{lm} S$ ribozyme can regulate gene expression in trans, small metabolite-sensing RNAs may also exist in nature.

\section{Conclusion and outlook}

Noncoding RNAs have been implicated in ever more cellular pathways and stress responses (Majdalani et al. 
2005; Storz et al. 2005). Besides the control of virulence and transcription factors (Romby et al. 2006; Wassarman 2007) and outer membrane protein biogenesis (Guillier et al. 2006; Vogel and Papenfort 2006), the regulation of metabolic sugar pathways has emerged as a major domain of bacterial sRNA action.

We have highlighted how the SgrS, Spot42, GlmY, and GlmZ sRNAs control the flux through central carbohydrate metabolic pathways. Much remains to be learned about each of these circuits. For example, the various phenotypes upon Spot42 overproduction suggest the existence of additional targets-e.g., in succinate metabolism-and Spot42 is predicted to pair with the $5^{\prime}$ end of sucC mRNA, encoding the $\beta$-subunit of succinyl-CoA synthetase (Møller et al. 2002b). Regarding SgrS, microarray analyses have predicted that in addition to ptsG, the mRNAs of the PTS sugar transporters specific for fructose and mannose are SgrS targets (see Vanderpool 2007). Similar analysis in Salmonella has shown that SgrS action extends beyond sugar regulation, and that by using the same binding region as for $p t s G$, SgrS regulates a laterally acquired Salmonella virulence factor (K. Papenfort and J. Vogel, in prep.). Note that there is an intimate connection between carbohydrate utilization and virulence in many pathogenic bacteria (Görke and Stülke 2008).

Global transcriptome analyses of $h f q$ mutants (Ding et al. 2004; Sonnleitner et al. 2006; Guisbert et al. 2007; Sittka et al. 2008) have revealed an extensive role of Hfq in the regulation of sugar pathways. Moreover, micoarray- or deep sequencing-based identification of Hfq-associated RNA (Zhang et al. 2003; Sittka et al. 2008) suggests that $\mathrm{Hfq}$ targets mRNAs not only of many sugar transporters and metabolic enzymes, but also of transcription factors that coordinate the uptake and utilization of carbohydrates. It is reasonable to predict that numerous of these Hfq-associated mRNAs will turn out as being targeted by sRNAs. Hfq also binds the mRNA coding for Crp (Sittka et al. 2008), and this global transcription factor in turn controls not only metabolic genes (Gutierrez-Rios et al. 2007), but also the synthesis of two sRNAs, Spot42, and CyaR (Polayes et al. 1988; Papenfort et al. 2008). All these observations suggest that we are just beginning to understand the manifold and widespread role for sRNAs in control of sugar metabolism.

This might also be true for metabolite-sensing ribozymes and riboswitches. We note that a potential riboswitch was identified upstream of the sucA gene in $\beta$ proteobacteria (Weinberg et al. 2007); SucA catalyzes a reaction in the Krebs cycle. In E. coli, the same function is encoded by sucC mRNA, which is a putative target of Spot42 sRNA (see above). Since riboswitches are abundant in low G + C Gram-positive bacteria such as B. subtilis but rare in E. coli (Barrick and Breaker 2007), it is tempting to speculate that regulation by trans-encoded sRNAs generally compensates for the much lower number of riboswitches in enteric bacteria. The documented differences in $g l m S$ regulation in $B$. subtilis (ribozyme) and $E$. coli (GlmYZ sRNAs) are in favor of this speculation.

\section{Acknowledgments}

We thank Hiroji Aiba, Carin Vanderpool, Susan Gottesman, Kai Papenfort, and Falk Kalamorz for discussions and comments on the manuscript. Work in our laboratories is supported by the Deutsche Forschungsgemeinschaft, including funds from the DFG Priority Program SPP1258, Sensory and Regulatory RNAs in Prokaryotes.

\section{References}

Altuvia, S., Weinstein-Fischer, D., Zhang, A., Postow, L., and Storz, G. 1997. A small, stable RNA induced by oxidative stress: Role as a pleiotropic regulator and antimutator. Cell 90: 43-53.

Altuvia, S., Zhang, A., Argaman, L., Tiwari, A., and Storz, G. 1998. The Escherichia coli OxyS regulatory RNA represses fhlA translation by blocking ribosome binding. EMBO $J$. 17: 6069-6075.

Argaman, L. and Altuvia, S. 2000. fhlA repression by OxyS RNA: Kissing complex formation at two sites results in a stable antisense-target RNA complex. I. Mol. Biol. 300: 1101-1112.

Argaman, L., Hershberg, R., Vogel, J., Bejerano, G., Wagner, E.G., Margalit, H., and Altuvia, S. 2001. Novel small RNAencoding genes in the intergenic regions of Escherichia coli. Curr. Biol. 11: 941-950.

Axmann, I.M., Kensche, P., Vogel, J., Kohl, S., Herzel, H., and Hess, W.R. 2005. Identification of cyanobacterial non-coding RNAs by comparative genome analysis. Genome Biol. 6: R73. doi: 10.1186/gb-2005-6-9-r73.

Babitzke, P. and Romeo, T. 2007. CsrB sRNA family: Sequestration of RNA-binding regulatory proteins. Curr. Opin. Microbiol. 10: 156-163.

Barrick, J.E. and Breaker, R.R. 2007. The distributions, mechanisms, and structures of metabolite-binding riboswitches. Genome Biol. 8: R239. doi: 10.1186/gb-2007-8-11-r239.

Barrick, J.E., Corbino, K.A., Winkler, W.C., Nahvi, A., Mandal, M., Collins, J., Lee, M., Roth, A., Sudarsan, N., Jona, I., et al. 2004. New RNA motifs suggest an expanded scope for riboswitches in bacterial genetic control. Proc. Natl. Acad. Sci. 101: 6421-6426.

Boisset, S., Geissmann, T., Huntzinger, E., Fechter, P., Bendridi, N., Possedko, M., Chevalier, C., Helfer, A.C., Benito, Y., Jacquier, A., et al. 2007. Staphylococcus aureus RNAIII coordinately represses the synthesis of virulence factors and the transcription regulator Rot by an antisense mechanism. Genes \& Dev. 21: 1353-1366.

Bott, M. 2007. Offering surprises: TCA cycle regulation in Corynebacterium glutamicum. Trends Microbiol. 15: 417-425.

Brennan, R.G. and Link, T.M. 2007. Hfq structure, function and ligand binding. Curr. Opin. Microbiol. 10: 125-133.

Cao, G.J. and Sarkar, N. 1992. Identification of the gene for an Escherichia coli poly(A) polymerase. Proc. Natl. Acad. Sci. 89: $10380-10384$.

Carpousis, A.J. 2007. The RNA degradosome of Escherichia coli: An mRNA-degrading machine assembled on RNase E. Annu. Rev. Microbiol. 61: 71-87.

Celesnik, H., Deana, A., and Belasco, J.G. 2007. Initiation of RNA decay in Escherichia coli by 5' pyrophosphate removal. Mol. Cell 27: 79-90.

Cochrane, J.C., Lipchock, S.V., and Strobel, S.A. 2007. Structural investigation of the GlmS ribozyme bound to its catalytic cofactor. Chem. Biol. 14: 97-105.

Collins, J.A., Irnov, I., Baker, S., and Winkler, W.C. 2007 
Mechanism of mRNA destabilization by the glmS ribozyme. Genes \& Dev. 21: 3356-3368.

Dam Mikkelsen, N. and Gerdes, K. 1997. Sok antisense RNA from plasmid R1 is functionally inactivated by RNase $\mathrm{E}$ and polyadenylated by poly(A) polymerase I. Mol. Microbiol. 26: 311-320.

Davis, B.M., Quinones, M., Pratt, J., Ding, Y., and Waldor, M.K. 2005. Characterization of the small untranslated RNA RyhB and its regulon in Vibrio cholerae. J. Bacteriol. 187: 40054014.

Deana, A. and Belasco, J.G. 2005. Lost in translation: The influence of ribosomes on bacterial mRNA decay. Genes \& Dev. 19: $2526-2533$.

Deutscher, J. 2008. The mechanisms of carbon catabolite repression in bacteria. Curr. Opin. Microbiol. 11: 87-93.

Deutscher, J., Francke, C., and Postma, P.W. 2006. How phosphotransferase system-related protein phosphorylation regulates carbohydrate metabolism in bacteria. Microbiol. Mol. Biol. Rev. 70: 939-1031.

Ding, Y., Davis, B.M., and Waldor, M.K. 2004. Hfq is essential for Vibrio cholerae virulence and downregulates $\sigma^{\mathrm{E}}$ expression. Mol. Microbiol. 53: 345-354.

Dreyfus, M. and Regnier, P. 2002. The poly(A) tail of mRNAs: Bodyguard in eukaryotes, scavenger in bacteria. Cell 111: 611-613.

Even, S., Pellegrini, O., Zig, L., Labas, V., Vinh, J., BrechemmierBaey, D., and Putzer, H. 2005. Ribonucleases J1 and J2: Two novel endoribonucleases in $B$. subtilis with functional homology to E. coli RNase E. Nucleic Acids Res. 33: 21412152.

Gancedo, J.M. 2008. The early steps of glucose signalling in yeast. FEMS Microbiol. Rev. 32: 673-704.

Görke, B. and Stülke, J. 2008. Carbon catabolite repression in bacteria: Many ways to make the most out of nutrients. Nat. Rev. Microbiol. 6: 613-624.

Guillier, M., Gottesman, S., and Storz, G. 2006. Modulating the outer membrane with small RNAs. Genes \& Dev. 20: 23382348.

Guisbert, E., Rhodius, V.A., Ahuja, N., Witkin, E., and Gross, C.A. 2007. Hfa modulates the $\sigma^{\mathrm{E}}$-mediated envelope stress response and the $\sigma^{32}$-mediated cytoplasmic stress response in Escherichia coli. J. Bacteriol. 189: 1963-1973.

Gutierrez-Rios, R.M., Freyre-Gonzalez, J.A., Resendis, O., Collado-Vides, J., Saier, M., and Gosset, G. 2007. Identification of regulatory network topological units coordinating the genome-wide transcriptional response to glucose in Escherichia coli. BMC Microbiol. 7: 53. doi: 10.1186/1471-2180-7-53.

Hammer, B.K. and Bassler, B.L. 2007. Regulatory small RNAs circumvent the conventional quorum sensing pathway in pandemic Vibrio cholerae. Proc. Natl. Acad. Sci. 104: 11145-11149.

Hatfull, G.F. and Joyce, C.M. 1986. Deletion of the spf (Spot 42 RNA) gene of Escherichia coli. J. Bacteriol. 166: 746-750.

Hershberg, R., Altuvia, S., and Margalit, H. 2003. A survey of small RNA-encoding genes in Escherichia coli. Nucleic Acids Res. 31: 1813-1820.

Huntzinger, E., Boisset, S., Saveanu, C., Benito, Y., Geissmann, T., Namane, A., Lina, G., Etienne, J., Ehresmann, B., Ehresmann, C., et al. 2005. Staphylococcus aureus RNAIII and the endoribonuclease III coordinately regulate spa gene expression. EMBO J. 24: 824-835.

Ikemura, T. and Dahlberg, J.E. 1973. Small ribonucleic acids of Escherichia coli. I. Characterization by polyacrylamide gel electrophoresis and fingerprint analysis. J. Biol. Chem. 248: 5024-5032.

Joanny, G., Le Derout, J., Brechemier-Baey, D., Labas, V., Vinh,
J., Regnier, P., and Hajnsdorf, E. 2007. Polyadenylation of a functional mRNA controls gene expression in Escherichia coli. Nucleic Acids Res. 35: 2494-2502.

Kalamorz, F., Reichenbach, B., Marz, W., Rak, B., and Görke, B. 2007. Feedback control of glucosamine-6-phosphate synthase GlmS expression depends on the small RNA GlmZ and involves the novel protein YhbJ in Escherichia coli. Mol. Microbiol. 65: 1518-1533.

Kawamoto, H., Morita, T., Shimizu, A., Inada, T., and Aiba, H. 2005. Implication of membrane localization of target mRNA in the action of a small RNA: Mechanism of post-transcriptional regulation of glucose transporter in Escherichia coli. Genes \& Dev. 19: 328-338.

Kawamoto, H., Koide, Y., Morita, T., and Aiba, H. 2006. Basepairing requirement for RNA silencing by a bacterial small RNA and acceleration of duplex formation by Hfq. Mol. Microbiol. 61: 1013-1022.

Kimata, K., Tanaka, Y., Inada, T., and Aiba, H. 2001. Expression of the glucose transporter gene, ptsG, is regulated at the mRNA degradation step in response to glycolytic flux in Escherichia coli. EMBO T. 20: 3587-3595.

Klein, D.J. and Ferre-D'Amare, A.R. 2006. Structural basis of glmS ribozyme activation by glucosamine-6-phosphate. Science 313: 1752-1756.

Kushner, S.R. 2004. mRNA decay in prokaryotes and eukaryotes: Different approaches to a similar problem. IUBMB Life 56: $585-594$.

Lapouge, K., Schubert, M., Allain, F.H., and Haas, D. 2008. Gac/ Rsm signal transduction pathway of $\gamma$-proteobacteria: From RNA recognition to regulation of social behaviour. Mol. Microbiol. 67: 241-253.

Lease, R.A., Cusick, M.E., and Belfort, M. 1998. Riboregulation in Escherichia coli: DsrA RNA acts by RNA:RNA interactions at multiple loci. Proc. Natl. Acad. Sci. 95: 1245612461.

Lenz, D.H., Mok, K.C., Lilley, B.N., Kulkarni, R.V., Wingreen, N.S., and Bassler, B.L. 2004. The small RNA chaperone Hfq and multiple small RNAs control quorum sensing in Vibrio harveyi and Vibrio cholerae. Cell 118: 69-82.

Liou, G.G., Jane, W.N., Cohen, S.N., Lin, N.S., and Lin-Chao, S. 2001. RNA degradosomes exist in vivo in Escherichia coli as multicomponent complexes associated with the cytoplasmic membrane via the $\mathrm{N}$-terminal region of ribonuclease $\mathrm{E}$. Proc. Nat1. Acad. Sci. 98: 63-68.

Liu, M.Y., Gui, G., Wei, B., Preston III, J.F., Oakford, L., Yuksel, U., Giedroc, D.P., and Romeo, T. 1997. The RNA molecule CsrB binds to the global regulatory protein CsrA and antagonizes its activity in Escherichia coli. J. Biol. Chem. 272: 17502-17510.

Liu, J.Y., Miller, P.F., Willard, J., and Olson, E.R. 1999. Functional and biochemical characterization of Escherichia coli sugar efflux transporters. J. Biol. Chem. 274: 22977-22984.

Lomas-Lopez, R., Paracuellos, P., Riberty, M., Cozzone, A.J., and Duclos, B. 2007. Several enzymes of the central metabolism are phosphorylated in Staphylococcus aureus. FEMS Microbiol. Lett. 272: 35-42.

Macek, B., Mijakovic, I., Olsen, J.V., Gnad, F., Kumar, C., Jensen, P.R., and Mann, M. 2007. The serine/threonine/tyrosine phosphoproteome of the model bacterium Bacillus subtilis. Mol. Cell. Proteomics 6: 697-707.

Majdalani, N., Cunning, C., Sledjeski, D., Elliott, T., and Gottesman, S. 1998. DsrA RNA regulates translation of RpoS message by an anti-antisense mechanism, independent of its action as an antisilencer of transcription. Proc. Natl. Acad. Sci. 95: 12462-12467.

Majdalani, N., Hernandez, D., and Gottesman, S. 2002. Regula- 
tion and mode of action of the second small RNA activator of RpoS translation, RprA. Mol. Microbiol. 46: 813-826.

Majdalani, N., Vanderpool, C.K., and Gottesman, S. 2005. Bacterial small RNA regulators. Crit. Rev. Biochem. Mol. Biol. 40: $93-113$.

Maki, K., Uno, K., Morita, T., and Aiba, H. 2008. RNA, but not protein partners, is directly responsible for translational silencing by a bacterial Hfq-binding small RNA. Proc. Nat1. Acad. Sci. 105: 10332-10337.

Massé, E. and Gottesman, S. 2002. A small RNA regulates the expression of genes involved in iron metabolism in Escherichia coli. Proc. Natl. Acad. Sci. 99: 4620-4625.

Massé, E., Escorcia, F.E., and Gottesman, S. 2003. Coupled degradation of a small regulatory RNA and its mRNA targets in Escherichia coli. Genes \& Dev. 17: 2374-2383.

Mathy, N., Benard, L., Pellegrini, O., Daou, R., Wen, T., and Condon, C. 2007. 5'-to-3' exoribonuclease activity in bacteria: Role of RNase J1 in rRNA maturation and 5' stability of mRNA. Cell 129: 681-692.

Milewski, S. 2002. Glucosamine-6-phosphate synthase-The multi-facets enzyme. Biochim. Biophys. Acta 1597: 173-192.

Miller-Hill, B. 1996. The lac operon: A short history of a genetic paradigm. de Gruyter, Berlin.

Moll, I., Afonyushkin, T., Vytvytska, O., Kaberdin, V.R., and Blasi, U. 2003. Coincident Hfq binding and RNase E cleavage sites on mRNA and small regulatory RNAs. RNA 9: 13081314.

Møller, T., Franch, T., Hojrup, P., Keene, D.R., Bachinger, H.P., Brennan, R.G., and Valentin-Hansen, P. 2002a. Hfq: A bacterial Sm-like protein that mediates RNA-RNA interaction. Mol. Cell 9: 23-30.

Møller, T., Franch, T., Udesen, C., Gerdes, K., and ValentinHansen, P. 2002b. Spot 42 RNA mediates discoordinate expression of the E. coli galactose operon. Genes \& Dev. 16: 1696-1706.

Morita, T., Kawamoto, H., Mizota, T., Inada, T., and Aiba, H. 2004. Enolase in the RNA degradosome plays a crucial role in the rapid decay of glucose transporter mRNA in the response to phosphosugar stress in Escherichia coli. Mol. Microbiol. 54: 1063-1075.

Morita, T., Maki, K., and Aiba, H. 2005. RNase E-based ribonucleoprotein complexes: Mechanical basis of mRNA destabilization mediated by bacterial noncoding RNAs. Genes \& Dev. 19: 2176-2186.

Morita, T., Mochizuki, Y., and Aiba, H. 2006. Translational repression is sufficient for gene silencing by bacterial small noncoding RNAs in the absence of mRNA destruction. Proc. Nat1. Acad. Sci. 103: 4858-4863.

Nanchen, A., Schicker, A., Revelles, O., and Sauer, U. 2008. Cyclic AMP-dependent catabolite repression is the dominant control mechanism of metabolic fluxes under glucose limitation in Escherichia coli. J. Bacteriol. 190: 2323-2330.

Novick, R.P., Ross, H.F., Projan, S.J., Kornblum, J., Kreiswirth, B., and Moghazeh, S. 1993. Synthesis of staphylococcal virulence factors is controlled by a regulatory RNA molecule. EMBO J. 12: 3967-3975.

Papenfort, K., Pfeiffer, V., Lucchini, S., Sonawane, A., Hinton, J.C., and Vogel, J. 2008. Systematic deletion of Salmonella small RNA genes identifies CyaR, a conserved CRP-dependent riboregulator of OmpX synthesis. Mol. Microbiol. 68: 890-906.

Plumbridge, J. 1995. Co-ordinated regulation of amino sugar biosynthesis and degradation: The NagC repressor acts as both an activator and a repressor for the transcription of the glmUS operon and requires two separated NagC binding sites. EMBO J. 14: 3958-3965.

Plumbridge, J. 2002. Regulation of gene expression in the PTS in Escherichia coli: The role and interactions of Mlc. Curr. Opin. Microbiol. 5: 187-193.

Polayes, D.A., Rice, P.W., Garner, M.M., and Dahlberg, J.E. 1988. Cyclic AMP-cyclic AMP receptor protein as a repressor of transcription of the spf gene of Escherichia coli. I. Bacteriol. 170: 3110-3114.

Prevost, K., Salvail, H., Desnoyers, G., Jacques, J.F., Phaneuf, E., and Masse, E. 2007. The small RNA RyhB activates the translation of shiA mRNA encoding a permease of shikimate, a compound involved in siderophore synthesis. Mol. Microbiol. 64: 1260-1273.

Reichenbach, B., Maes, A., Kalamorz, F., Hajnsdorf, E., and Gorke, B. 2008. The small RNA GlmY acts upstream of the sRNA GlmZ in the activation of glmS expression and is subject to regulation by polyadenylation in Escherichia coli. Nucleic Acids Res. 36: 2570-2580.

Rice, P.W. and Dahlberg, J.E. 1982. A gene between polA and glnA retards growth of Escherichia coli when present in multiple copies: Physiological effects of the gene for Spot 42 RNA. J. Bacteriol. 152: 1196-1210.

Rice, P.W., Polayes, D.A., and Dahlberg, J.E. 1987. Spot 42 RNA of Escherichia coli is not an mRNA. J. Bacteriol. 169: 38503852.

Rivas, E., Klein, R.J., Jones, T.A., and Eddy, S.R. 2001. Computational identification of noncoding RNAs in E. coli by comparative genomics. Curr. Biol. 11: 1369-1373.

Romby, P., Vandenesch, F., and Wagner, E.G. 2006. The role of RNAs in the regulation of virulence-gene expression. Curr. Opin. Microbiol. 9: 229-236.

Sahagan, B.G. and Dahlberg, J.E. 1979. A small, unstable RNA molecule of Escherichia coli: Spot 42 RNA. II. Accumulation and distribution. J. Mol. Biol. 131: 593-605.

Sharma, C.M., Darfeuille, F., Plantinga, T.H., and Vogel, J. 2007. A small RNA regulates multiple ABC transporter mRNAs by targeting C/A-rich elements inside and upstream of ribosome-binding sites. Genes \& Dev. 21: 2804-2817.

Sittka, A., Lucchini, S., Papenfort, K., Sharma, C.M., Rolle, K., Binnewies, T.T., Hinton, J.C.D., and Vogel, J. 2008. Deep sequencing analysis of small noncoding RNA and mRNA targets of the global post-transcriptional regulator, Hfq. PLOS Genet. 4: e1000163. doi: 10.1371/journal.pgen.1000163.

Sledjeski, D.D., Whitman, C., and Zhang, A. 2001. Hfq is necessary for regulation by the untranslated RNA DsrA. J. Bacteriol. 183: 1997-2005.

Söderbom, F., Binnie, U., Masters, M., and Wagner, E.G. 1997. Regulation of plasmid R1 replication: PcnB and RNase E expedite the decay of the antisense RNA, CopA. Mol. Microbiol. 26: 493-504.

Sonnleitner, E., Schuster, M., Sorger-Domenigg, T., Greenberg, E.P., and Blasi, U. 2006. Hfq-dependent alterations of the transcriptome profile and effects on quorum sensing in Pseudomonas aeruginosa. Mol. Microbiol. 59: 1542-1558.

Storz, G., Altuvia, S., and Wassarman, K.M. 2005. An abundance of RNA regulators. Annu. Rev. Biochem. 74: 199-217.

Tinsley, R.A., Furchak, J.R., and Walter, N.G. 2007. Trans-acting glmS catalytic riboswitch: Locked and loaded. RNA 13: 468-477.

Unoson, C. and Wagner, E.G. 2007. Dealing with stable structures at ribosome binding sites: Bacterial translation and ribosome standby. RNA Biol. 4: 113-117.

Urban, J.H. and Vogel, J. 2008. Two seemingly homologous noncoding RNAs act hierarchically to activate glmS mRNA translation. PLOS Biol. 6: e64. doi: 10.1371/journal. pbio.0060064. 
Urban, J.H., Papenfort, K., Thomsen, J., Schmitz, R.A., and Vogel, J. 2007. A conserved small RNA promotes discoordinate expression of the glmUS operon mRNA to activate GlmS synthesis. J. Mol. Biol. 373: 521-528.

Urbanowski, M.L., Stauffer, L.T., and Stauffer, G.V. 2000. The gcvB gene encodes a small untranslated RNA involved in expression of the dipeptide and oligopeptide transport systems in Escherichia coli. Mol. Microbiol. 37: 856-868.

Vanderpool, C.K. 2007. Physiological consequences of small RNA-mediated regulation of glucose-phosphate stress. Curr. Opin. Microbiol. 10: 146-151.

Vanderpool, C.K. and Gottesman, S. 2004. Involvement of a novel transcriptional activator and small RNA in post-transcriptional regulation of the glucose phosphoenolpyruvate phosphotransferase system. Mol. Microbiol. 54: 1076-1089.

Vogel, J. and Papenfort, K. 2006. Small non-coding RNAs and the bacterial outer membrane. Curr. Opin. Microbiol. 9: 605-611.

Vogel, J. and Sharma, C.S. 2005. How to find small non-coding RNAs in bacteria. Biol. Chem. 386: 1219-1238.

Vogel, J. and Wagner, E.G. 2007. Target identification of regulatory sRNAs in bacteria. Curr. Opin. Microbiol. 10: 262270.

Vogel, J., Bartels, V., Tang, T.H., Churakov, G., Slagter-Jager, J.G., Hüttenhofer, A., and Wagner, E.G. 2003. RNomics in Escherichia coli detects new sRNA species and indicates parallel transcriptional output in bacteria. Nucleic Acids Res. 31: 6435-6443.

Wadler, C.S. and Vanderpool, C.K. 2007. A dual function for a bacterial small RNA: SgrS performs base pairing-dependent regulation and encodes a functional polypeptide. Proc. Natl. Acad. Sci. 104: 20454-20459.

Wagner, E.G., Altuvia, S., and Romby, P. 2002. Antisense RNAs in bacteria and their genetic elements. Adv. Genet. 46: 361398.

Wassarman, K.M. 2007. 6S RNA: A regulator of transcription. Mol. Microbiol. 65: 1425-1431.

Wassarman, K.M., Repoila, F., Rosenow, C., Storz, G., and Gottesman, S. 2001. Identification of novel small RNAs using comparative genomics and microarrays. Genes \& Dev. 15: $1637-1651$.

Weinberg, Z., Barrick, J.E., Yao, Z., Roth, A., Kim, J.N., Gore, J., Wang, J.X., Lee, E.R., Block, K.F., Sudarsan, N., et al. 2007. Identification of 22 candidate structured RNAs in bacteria using the CMfinder comparative genomics pipeline. Nucleic Acids Res. 35: 4809-4819.

Wilderman, P.J., Sowa, N.A., FitzGerald, D.J., FitzGerald, P.C., Gottesman, S., Ochsner, U.A., and Vasil, M.L. 2004. Identification of tandem duplicate regulatory small RNAs in Pseudomonas aeruginosa involved in iron homeostasis. Proc. Natl. Acad. Sci. 101: 9792-9797.

Wilson, D.B. and Hogness, D.S. 1969. The enzymes of the galactose operon in Escherichia coli. IV. The frequencies of translation of the terminal cistrons in the operon. J. Biol. Chem. 244: 2143-2148.

Winkler, W.C., Nahvi, A., Roth, A., Collins, J.A., and Breaker, R.R. 2004. Control of gene expression by a natural metabolite-responsive ribozyme. Nature 428: 281-286.

Worrall, J.A.R., Górna, M., Crumpa, N.T., Phillips, L.G., Tucka, A.C., Price, A.J., Bavroa, V.N., and Luisi, B.F. 2008. Reconstitution and analysis of the multienzyme Escherichia coli RNA degradosome. J. Mol. Biol. 382: 870-883.

Xu, F., Lin-Chao, S., and Cohen, S.N. 1993. The Escherichia coli $p c n B$ gene promotes adenylylation of antisense RNAI of ColE1-type plasmids in vivo and degradation of RNAI decay intermediates. Proc. Nat1. Acad. Sci. 90: 6756-6760.
Zhang, A., Altuvia, S., Tiwari, A., Argaman, L., Hengge-Aronis, R., and Storz, G. 1998. The OxyS regulatory RNA represses rpoS translation and binds the Hfq (HF-I) protein. EMBO $\mathrm{I}$. 17: 6061-6068.

Zhang, A., Wassarman, K.M., Ortega, J., Steven, A.C., and Storz, G. 2002. The Sm-like Hfq protein increases OxyS RNA interaction with target mRNAs. Mol. Cell 9: 11-22.

Zhang, A., Wassarman, K.M., Rosenow, C., Tjaden, B.C., Storz, G., and Gottesman, S. 2003. Global analysis of small RNA and mRNA targets of Hfq. Mol. Microbiol. 50: 1111-1124. 


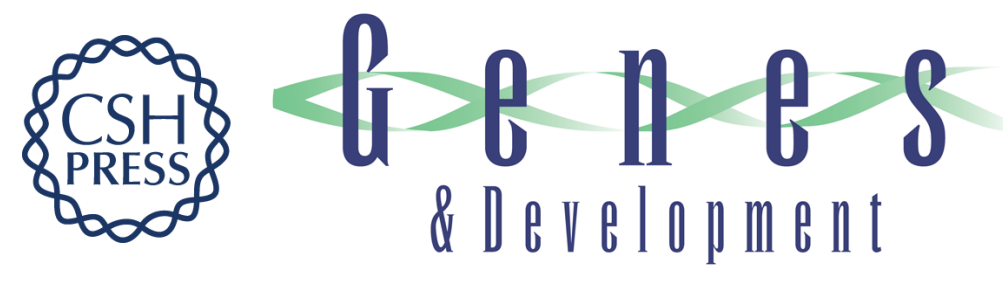

\section{Noncoding RNA control of the making and breaking of sugars}

Boris Görke and Jörg Vogel

Genes Dev. 2008, 22:

Access the most recent version at doi:10.1101/gad.1717808

References This article cites 106 articles, 43 of which can be accessed free at: http://genesdev.cshlp.org/content/22/21/2914.full.html\#ref-list-1

License

Email Alerting Receive free email alerts when new articles cite this article - sign up in the box at the top Service right corner of the article or click here.

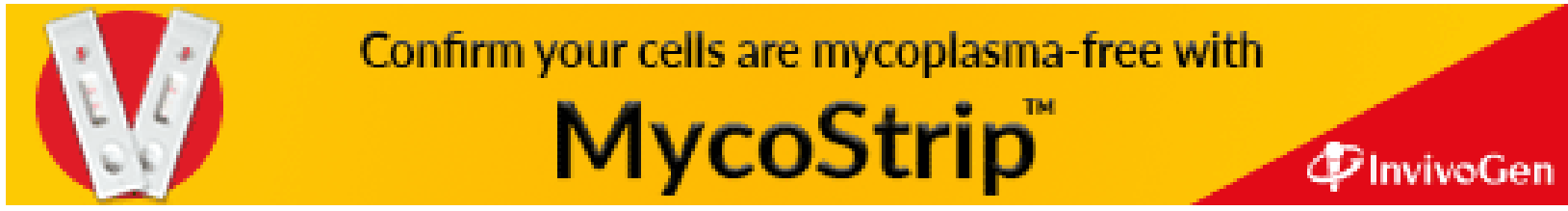

